\title{
As variáveis social e afetiva como potencializadoras da aquisição da segunda língua
}

\author{
The social and affective variables as enhancing factors for the acquisition of a second \\ language \\ Gladys QUEVEDO-CAMARGO* \\ Universidade de Brasília (UnB) \\ Makoy SANTOS DA SILVA** \\ Secretaria Estadual de Educação do Pará (SEDUC-PA) \\ Secretaria Municipal de Educação de Belém (SEMEC-Belém)
}

RESUMO: Objetivamos, neste trabalho, discutir a importância das variáveis social e afetiva como potencializadoras da aquisição de uma segunda língua. Entendemos que as variáveis social e afetiva muito podem contribuir para o desenvolvimento da língua-alvo, uma vez que este é influenciado pela integração social e psicológica do aprendiz com grupos que falam essa língua. Acreditamos que esses grupos não se limitam apenas aos falantes nativos, mas a todo aquele que se identifica sociopsicologicamente com a língua-alvo com o objetivo de adquiri-la. A metodologia utilizada foi a pesquisa bibliográfica (MARCONI; LAKATOS, 2003; PRODANOV; FREITAS, 2013). Como aportes teóricos, recorremos aos estudos da Aquisição de Segunda Língua (ASL) tendo como representantes Correa (1999), Gass e Selinker (2008), Larsen-Freeman (2011), Paiva (2011), e VanPatten e Williams (2015); na Teoria do Modelo Monitor, Krashen (1985); e no Modelo de Aculturação, Schumann (1986). Nosso objetivo é contribuir para que professores de línguas, estudantes do Curso de Letras, assim como alunos da pós-graduação em Linguística Aplicada possam refletir sobre a relevância deste estudo e compreender que as variáveis social e afetiva podem ajudar no progresso da aquisição da língua estudada.

\footnotetext{
* Doutora em Estudos da Linguagem pela Universidade Estadual de Londrina e pós-doutorado pela Universidade Estadual de Campinas (UNICAMP), com pesquisa na área de avaliação de línguas. Professora adjunta do Departamento de Línguas Estrangeiras e Tradução (LET) e do Programa de Pós-Graduação em Linguística Aplicada - PGLA da Universidade de Brasília (UnB). E-mail: gladys @ unb.br

** Mestre em Linguística Aplicada pela Universidade de Brasília - UnB (2019), Especialista em Linguística Aplicada ao Ensino do Inglês como Língua Estrangeira pela UFPA (2006/2007), Graduado em Letras (Português/Inglês) pela Universidade Federal do Pará - UFPA (2004/2006), professor efetivo da Secretaria Estadual de Educação do Pará (SEDUC-PA) e da Secretaria Municipal de Educação de Belém (SEMEC-Belém). E-mail: makoysantos@yahoo.com.br
}

Revista Moara, n. 54, ago-dez 2019 ISSN: 0104-0944

Recebido em 07/10/2019

Avaliado em 18/11/2019 
PALAVRAS-CHAVE: Variável social. Variável afetiva. Aquisição de Segunda língua (ASL). Formação de professores de línguas.

ABSTRACT: The objective of this paper is to discuss the importance of social and affective variables as enhancers of the acquisition of a second language. We understand that they can greatly contribute to the progress of the target language as it is influenced by the learner's social and psychological integration with groups that speak the language. We believe that these groups are not limited only to native speakers, but to anyone who identifies themselves sociopsychologically with the target language in order to acquire it. The methodology used was bibliographical research (MARCONI; LAKATOS, 2003; PRODANOV; FREITAS, 2013). As theoretical contributions, we rely on the studies about Second Language Acquisition (SLA), having as representatives Correa (1999), Gass and Selinker (2008), Larsen-Freeman (2011), Paiva (2011), and VanPatten and Williams (2015); on the Monitor Model Theory, Krashen (1985); and on the Acculturation Model, Schumann (1986). The expected outcome is to provide foreign language teachers, students of Modern Language Courses, as well as postgraduate students in Applied Linguistics with the opportunity to reflect upon the relevance of this study and to contribute to the understanding that both social and affective variables can help in language acquisition.

KEYWORDS: Social variable. Affective variable. Second Language Acquisition (SLA). Language teacher education.

\section{Introdução}

Muito do que se sabe hoje sobre aquisição de segunda língua (ASL) deriva de literatura estrangeira, principalmente de origem anglo-saxônica, tendo como grandes expoentes autores como VanPatten e Williams (2015), Ellis (2008), Gass e Selinker (2008), Brown (2007), Littlewood (1984), Cook (1993) e Larsen-Freeman e Long (1991). Essa literatura ganha forças nas universidades brasileiras, sendo objeto de estudos e pesquisas tanto nos cursos de graduação quanto nos de pós-graduação dos cursos de Letras, tendo notoriedade, principalmente, na área da Linguística Aplicada (LA).

De acordo com Moita Lopes (1996), a Linguística Aplicada é uma ciência social de estudos de linguagem de caráter interdisciplinar que focaliza questões de uso da 
linguagem em diferentes contextos, seja no âmbito de ensino-aprendizagem quanto fora dele. Em outras palavras, entende-se que é possível lançar mão de conhecimentos das mais variadas áreas com diferentes propósitos comunicativos e interacionais.

Os autores que abordam a aquisição de segunda língua tentam elucidar como acontece esse processo, explicando minuciosamente como se configura cada etapa. Entretanto, nem sempre há consenso entre eles, ao ponto de encontrarmos na literatura “pelo menos quarenta 'teorias' de ASL” (LARSEN-FREEMAN; LONG, 1991, p. 227). Apesar disso, de acordo com Paiva (2009, p. 1), “ainda não se chegou a um consenso sobre como aprendemos uma língua, pois nenhuma dessas propostas apresenta uma explicação completa do fenômeno".

Os diferentes entendimentos sobre as teorias da aquisição de segunda língua têm gerado controvérsias em virtude de sua complexidade, porém, conhecer o processo de ASL é vital e de extrema importância, principalmente, para professores de línguas materna e estrangeira. Ademais, esse conhecimento pode trazer subsídios teóricos e epistemológicos que alicerçam o fazer profissional e embasam o profissionalismo docente.

Nessa perspectiva, compactuamos com a percepção de Ortega (2013) sobre a ASL. Segundo a autora, a ASL é o

\begin{abstract}
campo acadêmico de investigação que perscruta a capacidade humana de aprender outras línguas além da primeira, e que também estuda uma ampla variedade de influências e fenômenos complexos que contribuem para uma gama de resultados possíveis quando se aprende uma outra língua em uma variedade de contextos ${ }^{1}$. (ORTEGA, 2013, p. 1).
\end{abstract}

Apesar de tantas controvérsias e inúmeras tentativas teóricas para explicar como acontece o processo de ASL, depreendemos que essas teorias podem trazer luzes e ampliar o entendimento acerca de como se dá a aquisição de qualquer língua humana. E, por ser um processo complexo, acreditamos também que sua realização pode acontecer em circunstâncias e ambientes variados, que vão desde uma imersão em loco em países

\footnotetext{
${ }^{1}$ Esta tradução e as demais que integram este texto são de nossa autoria. Original: Second language acquisition (SLA, for short) is the scholarly field of inquiry that investigates the human capacity to learn languages other than the first, and it studies a wide variety of complex influences and phenomena that contribute to the puzzling range of possible outcomes when learning an additional language in a variety of contexts.
} 
que falam a língua-alvo, onde a aquisição pode ocorrer incidentalmente (LANTOLF; THORNE; POEHNER, 2015) até em ambientes mais formais de aprendizagem da língua em países que não compartilham da mesma raiz linguística da língua estudada.

Nossa concepção de língua é a de uso, isto é, a língua empregada em sua função instrumental e social para atingir objetivos específicos (LANTOLF; THORNE; POEHNER, 2015). Logo, reconhecemos que o desenvolvimento da competência linguístico-comunicativa (CLC) é condição para a aquisição de uma língua, cooperando também para a melhora da proficiência do uso oral da língua dos aprendizes. De forma semelhante, assentimos que, em se tratando do ensino da língua-alvo, professores de língua estrangeira (LE), munidos dessa compreensão, contribuem para "atuar como um modelo linguístico e assim colaborar, por meio de sua fala, no processo de geração de insumo adequado aos alunos" (CONSOLO; SILVA, 2011, p. 130), permitindo, dessa forma, um maior engajamento na interação verbal e o desenvolvimento dessa proficiência.

Mesmo cientes da complexidade do construto proficiência, entendemos que o termo deve ser visto como um conceito relativo, e não absoluto. Ou seja, não fruto de “julgamentos impressionistas, feitos de forma holística, do desempenho geralmente oral de um falante de L2 ou LE" (SCARAMUCCI, 2000, p. 3), e sim resultado do uso da língua em situação real. Para Quevedo-Camargo (2019), a relatividade do construto proficiência se deve ao fato de que seu escopo

\begin{abstract}
foi gradativamente expandindo e incorporando aspectos que vão muito além de saber gramática ou vocabulário. Esses aspectos se referem diretamente ao uso real da língua para comunicação em situações reais, de forma social e culturalmente adequada. (QUEVEDO-CAMARGO, 2019, p. 41).
\end{abstract}

A autora ainda argumenta que o conceito proficiência se desenvolve parcial e gradativamente em diferentes aspectos e suas implicações acabam impactando o mundo real do ensino, no que se refere à elaboração e escolha de materiais e livros didáticos; da aprendizagem, no que concerne a contribuir com o desenvolvimento da proficiência do aluno e da avaliação de línguas no Brasil, concebida a partir da perspectiva não monolítica do construto proficiência, assumindo, com isso, "uma característica essencialmente comunicativa por estar alicerçada em necessidades comunicativas sociais reais" (QUEVEDO-CAMARGO, 2019, p. 42). 
Quanto ao desenvolvimento da competência linguístico-comunicativa na línguaalvo, pensamos que os fatores propostos por Schumann (1978), dentre eles as variáveis social e afetiva, muito podem contribuir para o progresso da aquisição de uma segunda língua. De acordo com o autor, essas variáveis são extraídas da teoria do Modelo de Aculturação, a qual vê "a integração social e psicológica do aprendiz com o grupo da língua-alvo" (SCHUMANN, 1978, p. 29).

Entretanto, ao se falar de "integração social e psicológica do aprendiz com o grupo da língua-alvo" é importante ressaltar que vivemos em uma época totalmente diferente da que se encontrava Schumann, tanto no aspecto sociocultural quanto no que concerne às teorias desenvolvidas, até o momento, acerca da ASL. Para o autor, uma aquisição efetiva só aconteceria por meio de uma integração sociopsicológica com nativos da língua. Porém, se levarmos em consideração a atual época globalizada em que a internacionalização do processo de aprendizagem é muito mais dinâmica, certamente, nos depararemos com uma gama de possibilidades que contribuem para o processo de aquisição da língua estudada.

Essa gama de possibilidades está, por exemplo, nas inovações tecnológicas, as quais nos possibilitaram estar, através da Internet, e instantaneamente, em contato com falantes nativos, assim como abrem margens para a criação de plataformas e aplicativos gratuitos direcionados ao ensino da língua, como DuoLingo, Anki, Tandem, HelloTalk, Hello Pal, que ajudam no desenvolvimento desse processo. Logo, a atual conjuntura global nos permite dizer que as barreiras físicas e espaciais não mais são obstáculos para que o aprendiz se envolva afetiva e psicologicamente com uma segunda língua.

Assim, diante dessas reflexões, trazemos a necessidade de se discutir a relevância das variáveis social e afetiva de Schumann, sob uma perspectiva atual, como possíveis viabilizadoras para o desenvolvimento da aquisição de uma segunda língua. Acreditamos que os princípios da Teoria da Aculturação do autor ainda são úteis e trazem benefícios para o aprendiz da língua-alvo. Para isso, abordamos, primeiramente, o que se entende sobre as teorias da ASL, respaldando esta seção com pressupostos teóricos a fim de elucidar uma maior compreensão do termo. Em seguida, apresentamos as duas teorias fundamentais: a Behaviorista e a do Modelo Monitor. Nossa escolha se baseia no fato da primeira apresentar princípios linguísticos e psicológicos que buscam explicar a aprendizagem e fornecer orientações sobre seu ensino; a segunda, por 
entendermos que esse modelo sofre forte influência da concepção que se tem sobre língua e aquisição. Na sequência, analisamos a teoria do Modelo de Aculturação de Schumann, com ênfase nas variáveis social e afetiva.

\section{Aquisição de Segunda Língua (ASL)}

O estudo da aquisição de línguas tem por objetivo explicar de que modo o ser humano parte de um estado no qual não possui qualquer forma de expressão verbal e, naturalmente, ou seja, "sem a necessidade de aprendizagem formal, incorpora a língua de sua comunidade nos primeiros anos de vida, adquirindo um modo de expressão e de interação social dela dependente" (CORREA, 1999, p. 339).

Correa (1999) endossa que a aquisição de cada língua requer a identificação de seu sistema fonológico, sua morfologia, seu léxico, o que há de peculiar em sua sintaxe e no modo como as relações semânticas se estabelecem. Entretanto, não há unanimidade no estudo da aquisição da linguagem, no que diz respeito ao desenvolvimento do estado inicial e final desse processo.

A autora destaca duas principais razões para a falta de consonância: a "duplicidade de objetos a que o termo linguagem pode remeter, o que dá margem a diferentes modos de se conceber o problema de aquisição, a outra, ocorre em decorrência do confronto de diferentes tradições ou posturas epistemológicas no tratamento de um problema interdisciplinar" (CORREA, 1999, p. 340).

Semelhantemente ao posicionamento de Correa, Gass e Selinker (2008) enfatizam que a aquisição de segunda língua, estudada e analisada por vários autores, ainda está longe de apresentar uma teoria completa. Porém, nos últimos sessenta anos houve progresso, ao ponto de impactar outras áreas de estudo, tais como a Linguística, a Psicologia, a Psicolinguística, a Sociologia, a Sociolinguística, a Análise do Discurso, a Análise Conversacional, e a Educação, apenas para nomear algumas.

Com o objetivo de familiarizar o leitor acerca do que é aquisição de segunda língua, Gass e Selinker (2008) trazem alguns conceitos que lançam luz sobre o termo. Segundo os autores, a ASL: 
É o estudo de como as segundas línguas são aprendidas.

É o estudo da aquisição de uma língua não primária, isto é, a aquisição de uma língua além da língua nativa.

É o estudo de como os aprendizes criam um novo sistema de idiomas com exposição limitada a uma segunda língua.

É o estudo do por quê a maioria dos aprendizes de segunda língua não atinge o mesmo grau de conhecimento e proficiência em uma segunda língua como no seu idioma nativo. (GASS; SELINKER, 2008, p. 1). ${ }^{2}$

Além de conceituar ASL, Gass e Selinker (2008) também endossam que a aprendizagem de uma língua não deriva de processos de memorização de regras, nem é fruto de repetições de sentenças ou estruturas gramaticais, mas é, sim, resultado da expressão comunicativa, como constatado a seguir:

Os detalhes desta nova conceituação da aprendizagem de línguas resultaram em metodologias que enfatizam a comunicação. Em outras palavras, a tomada de decisão pedagógica deve refletir o que se sabe sobre o processo de aprendizagem, que é o domínio da aquisição da segunda língua. (GASS; SELINKER, 2008, p. 3). ${ }^{3}$

Como visto, as teorias da aquisição de segunda língua, ainda que complexas, lançam luz sobre o campo do ensino de línguas, fazendo com que a tomada de decisão pedagógica tenha reflexos sobre o próprio processo de aprendizagem.

Quanto à complexidade, Larsen-Freeman e Cameron (2008, p. 38) enfatizam que, na aquisição de segunda língua, a língua é vista como um "sistema dinâmico, aberto e nunca completamente adquirido". Sobre esse assunto, Paiva (2011) destaca que a Teoria da Complexidade tornou-se mais do que uma metáfora e é hoje um novo paradigma na ciência, possibilitando conceitos que nos fazem entender diferentes fenômenos em diferentes áreas do conhecimento, incluindo a Linguística Aplicada.

Com o intuito de exemplificar quão multifacetada é essa teoria, Paiva (2011) descreve abaixo um breve panorama sobre o paradigma da Complexidade nas mais diferentes áreas de conhecimento. A saber:

\footnotetext{
${ }^{2}$ Original: It is the study of how second languages are learned. / it is the study of the acquisition of a nonprimary language; that is, the acquisition of a language beyond the native language. / It is the study of how learners create a new language system with only limited exposure to a second language. / it is the study of why most second language learners do not achieve the same degree of knowledge and proficiency in a second language as they do in their native language.

${ }^{3}$ Original: The details of this new conceptualization of language learning have resulted in methodologies that emphasize communication. In other words, pedagogical decision-making must reflect what is known about the process of learning, which is the domain of second language acquisition.
}

Revista Moara, n. 54, ago-dez 2019 ISSN: 0104-0944

Recebido em 07/10/2019

Avaliado em 18/11/2019 
Em matemática, Poincaré (1921) demonstrou que mesmo os sistemas cujos comportamentos são bem conhecidos exibem comportamentos indeterminados e Mandelbrot (1982) comprovou, com a geometria fractal, como as características do todo se reproduzem nas partes em alguns fenômenos. Em meteorologia, Lorenz (2001) cunhou a metáfora do efeito borboleta para representar a noção da dependência sensível às condições iniciais na teoria do caos, ou seja, a ideia de que pequenas alterações no sistema podem provocar enormes consequências. (PAIVA, 2011, p. 1).

Considerando o breve panorama sobre o paradigma da Complexidade, compreendemos que Paiva entende o processo de desenvolvimento de uma segunda língua como um sistema complexo, o qual ela própria denomina de Modelo Fractal de Aquisição de Línguas, que busca conceber que os processos de aprendizagem não são semelhantes, e sim, caóticos e imprevisíveis. Ou seja, a autora argumenta que a aprendizagem de línguas, como um fenômeno complexo, se apresenta de forma imprevisível e está em constante evolução, endossando que o processo de aquisição de uma língua evidencia um caráter dinâmico, complexo e não-linear da linguagem.

Em suas análises sobre as teorias da ASL, VanPatten e Williams (2015, p. 17) consideram dois grandes períodos de conhecimento e divulgação teórica. O primeiro, vindo de teorias originadas da psicologia, das quais a Linguística Aplicada se apropriou para elucidar a Teoria Behaviorista e as abordagens estruturalistas do estudo da linguagem. O segundo período, que também teve relevante impacto na Linguística Aplicada, tem como seu precursor Stephen Krashen, na denominada Teoria do Modelo Monitor. As duas teorias são apresentadas a seguir.

\subsection{A Teoria Behaviorista}

O Behaviorismo tem como seu precursor John Broadus Watson, que, na verdade, "se intitula o fundador do behaviorismo" (PAIVA, 2014, p. 12) e passa a ser defensor da psicologia como ciência natural e da necessidade de a psicologia se tornar uma disciplina aplicada. Sob a influência do positivismo, o autor respalda seus estudos em pesquisas experimentais, logo, rejeita a consciência e o subjetivismo e considera que a matéria de interesse da psicologia é o comportamento humano. Segundo Cohen (1979), Watson é descrito por um dos seus biógrafos como tendo "provavelmente 
influenciado a psicologia [norte americana] tanto quanto, ou mesmo mais, que Freud" (COHEN, 1979, p.1) $)^{4}$.

Palavra de origem inglesa, o termo behavior significa comportamento, daí a razão de usarmos, no Brasil, Behaviorismo como Comportamentalismo, Análise Experimental do Comportamento, entre outros. O Behaviorismo tem sua origem como uma teoria que estuda experimentalmente o comportamento animal e humano, e esse comportamento é explicado unicamente com referência a fatores externos, como estímulo, resposta, repetição, ação reflexa, frequência e condicionamento, ou seja, essa teoria não concebe ou reconhece explicações mentalistas, tampouco foi cogitada sua aplicabilidade em salas de aula.

Segundo essa teoria, a exposição repetida é um fator importante no desenvolvimento de novos comportamentos, levando os behavioristas a alegarem que poderia haver uma associação entre as próprias respostas, que inicialmente são desencadeadas pelo estímulo externo, o que se convenciou chamar de condicionamento operante ou comportamental. No condicionamento operante, "um organismo pode ser condicionado a se engajar em um comportamento mesmo quando o estímulo não está mais presente se ele aprendeu a associação relevante através de feedback consistente ${ }^{5}$ (VANPATTEN; WILLIAMS, 2015, p. 19).

Segundo os behavioristas, isso é mais uma indicação de que os processos mentais são puramente resultados da associação de eventos, uma resposta a estímulos ambientais e subsequente reforço ou punição; logo, acredita-se que o reforço fortalece a continuação do comportamento de resposta, enquanto a punição enfraquece.

Entretanto, uma teoria que foi primeiramente pautada no comportamento de animais encontra refutações e contrasta fortemente com abordagens de aprendizagem que se seguiram, pois, segundo o behaviorismo, o objeto de estudo é observável e mensurável, ou seja, a observação direta do comportamento é o único método seguro que esses estudiosos consideram para se produzir conhecimento científico em psicologia, tendo, portanto, um "caráter epistemológico na medida em que versa sobre o modo mais seguro de se conhecer o objeto de estudo" (STRAPASSON, 2012, p. 83) .

\footnotetext{
${ }^{4}$ No original: probably influenced psychology as much or even more than Freud.

${ }^{5}$ No original: In operant conditioning, an organism can be conditioned to engage in a behavior even when the stimulus is no longer present if it has learned the relevant association through consistent feedback.

Revista Moara, n. 54, ago-dez 2019 ISSN: 0104-0944

Recebido em 07/10/2019

Avaliado em 18/11/2019
} 
Ao se falar de ensino de línguas e behaviorismo, Burrhus Frederic Skinner é o nome mais lembrado. $\mathrm{O}$ autor reitera que o comportamento é reforçado pela mediação de outra pessoa, ou seja, "em todo comportamento verbal, há três eventos importantes a serem considerados: um estímulo, uma resposta e um reforço" (SKINNER, 1992, p. 81). Por conseguinte, a aprendizagem na perspectiva behaviorista de Skinner é fruto de um comportamento observável, adquirido de forma mecânica e automática por meio de estímulos e respostas.

Assim, para os behavioristas, todo aprendizado - incluindo o aprendizado de línguas - é visto como a aquisição de um novo comportamento, tendo o ambiente como fator primordial para a aprendizagem, ou seja, a aprendizagem consiste em desenvolver respostas aos estímulos ambientais. Logo, na perspectiva behaviorista, a aprendizagem de uma segunda língua (L2) é o resultado da imitação de modelos corretos repetidamente, acontecendo, portanto, por analogia, como constatado a seguir:

\begin{abstract}
Assim, a aprendizagem de línguas é vista como semelhante a qualquer outro tipo de aprendizagem: imitação de modelos no input, prática do novo comportamento e fornecimento de feedback apropriado. (VANPATTEN; WILLIAMS, 2015, p. 19). ${ }^{6}$
\end{abstract}

Enfim, de acordo com o Behaviorismo, a ASL, além de ocorrer por imitação de modelos corretos repetidamente, pode ocorrer também por analogia, ratificando o reforço positivo de imitações precisas e correção daquelas que não são. Todavia, ressaltamos que a teoria behaviorista não é unanimidade e encontra resistência entre os pesquisadores de ASL, pois a ênfase questionada desta teoria se detém em descrever o que é diretamente observável, ou seja, para esses teóricos, a aquisição da língua é "vista como um processo de imitação e repetição do que foi ouvido"7 e "não se detém em comunicar significado e sim apresentar simplesmente um modelo de língua"8 (VANPATTEN; WILLIAMS, 2015, p. 21-22), o que, em nossa opinião, provavelmente, não explica como acontecem os processos de aquisição da língua estudada. E, mesmo

\footnotetext{
${ }^{6}$ No original: Thus, language learning is seen as similar to any other kind of learning, from multiplication to yodeling: imitation of models in the input, practice of the new behavior, and the provision of appropriate feedback.

${ }^{7}$ No original: language was seen a process of imitation and repetition of what was heard. (p. 21).

${ }^{8}$ No original: it was not intended to communicate meaning but to simply model language. (p. 22).

Revista Moara, n. 54, ago-dez 2019 ISSN: 0104-0944 
que a teoria behaviorista não apresente argumentos convincentes sobre a ASL, não se pode dizer que essa teoria não influenciou e continua influenciando o ensino de línguas.

Como visto, na perspectiva behaviorista, a ASL suscita indagações de como ocorre esse processo, levando estudiosos como Dulay e Burt (1975) a proporem a Hipótese da Construção Criativa, a qual sustentava que o processo de aquisição de idiomas envolve um transcurso criativo no qual o aprendiz formula hipóteses inconscientes com base em informações (Input). De acordo com essa hipótese, "o processamento de insumos é, por sua vez, controlado por mecanismos inatos, os mesmos que operam na aquisição da primeira língua"9 (VANPATTEN; WILLIAMS, 2015 , p. 24).

Esses estudos trouxeram subsídios para que Stephen Krashen formulasse sua teoria, ao final da década de 1970, chamada Teoria do Modelo Monitor, e escolhida por nós por ter sido a primeira no campo com tamanha amplitude no escopo, e que tentou relacionar e explicar uma variedade de fenômenos no aprendizado de idiomas, que vão desde o efeito da idade na ASL aos efeitos aparentemente desiguais da instrução. A seguir, a Teoria do Modelo Monitor.

\subsection{A Teoria do Modelo Monitor}

Em 1978, Stephen Krashen apresenta a Teoria do Modelo Monitor, também conhecida como Hipótese do Input, e, mais atualmente, como Hipótese da Compreensão. Esse modelo sofreu grandes influências da concepção de língua e do que se entende hoje sobre a dicotomia entre os termos competência e desempenho (expressões cunhadas por Chomsky), postulados na Linguística, e dos termos aquisição e aprendizagem (vocábulos creditados à Krashen). Segundo a Teoria do Modelo Monitor, o processo de ensino-aprendizagem ocorre de duas formas: através da hipótese da aquisição inconsciente e da hipótese da aprendizagem consciente.

A dicotomia entre aquisição e aprendizagem de Krashen tornou-se uma das questões mais citadas e criticadas no ensino de línguas na área da Linguística Aplicada, pois, para o autor, a aquisição é resultado de um processo automático que se desenvolve no nível do subconsciente, ou seja, sem esforço consciente por parte do indivíduo, e é

\footnotetext{
${ }^{9}$ No original: The processing of input is, in turn, controlled by innate mechanisms, the same ones that operate in first language acquisition.

Revista Moara, n. 54, ago-dez 2019 ISSN: 0104-0944

Recebido em 07/10/2019

Avaliado em 18/11/2019
} 
semelhante ao processo de aquisição da língua materna. A aprendizagem, por sua vez, é fruto de um processo consciente que resulta do conhecimento formal sobre a língua.

Contudo, para McLaughlin (1987), essas hipóteses são questionáveis porquanto Krashen não define de forma clara os termos aquisição, aprendizagem, consciente e subconsciente, "tornando assim impossível determinar exatamente o que seriam língua adquirida e língua aprendida"10 (MCLAUGHLIN, 1987, p. 21).

Por outro lado, para VanPatten e Williams (2015), embora os processos reais envolvidos na aprendizagem não sejam explicados, Krashen tenta explicar a aquisição por meio de hipóteses, que muito contribuíram para se entender as pesquisas sobre aquisição de línguas estrangeiras.

Semelhantemente, Paiva (2014, p. 34) corrobora a ideia de que

se o modelo não convence a comunidade científica, um mérito não pode deixar de ser reconhecido - sua contribuição para o desenvolvimento dos estudos em aquisição de segunda língua, instigando os pesquisadores a refutar suas hipóteses.

A autora ainda argumenta que as críticas às hipóteses de aquisição e aprendizagem de Krashen surgem em virtude da própria vagueza das definições de seus conceitos e a impossibilidade de verificação empírica de suas hipóteses, e "algumas dessas críticas ainda são fruto do apego ao objetivismo, só aceitando aquilo que é observável" (PAIVA, 2014, p. 48). Contudo, apesar da inconsistência de uma definição precisa, Gass e Selinker (1994) endossam que a teoria de Krashen

gerou inúmeros projetos de pesquisa, o que fez com que a área de aquisição de segunda língua avançasse muitos passos à frente, focando a atenção, particularmente, em áreas inexploradas. ${ }^{11}$ (GASS; SELINKER, 1994, p. 151).

A Teoria do Modelo Monitor, além de contribuir para os avanços na área de ASL, também possibilitou reflexionar acerca de outras questões amplamente divulgadas no ensino de línguas, tais como:

\footnotetext{
${ }^{10}$ No original: thus making it impossible to determine exactly what would be acquired language and learned language.

${ }^{11}$ No original: Krashen's theory spawned numerous research projects, which led the area of second language acquisition to advance many steps forward, focusing attention particularly on unexplored areas.

Revista Moara, n. 54, ago-dez 2019 ISSN: 0104-0944

Recebido em 07/10/2019

Avaliado em 18/11/2019
} 
[a] Hipótese da ordem natural: esta hipótese ratifica que se aprende as regras da língua em uma ordem natural ou previsível, ou seja, para que ocorra o processo de aquisição de uma língua, aprendizes precisam seguir sequências de formas específicas, tais como os morfemas gramaticais ing-, -ed, $-s$ e outros, na língua inglesa, por exemplo. Segundo a Teoria do Modelo Monitor, “essas regularidades ocorrem porque toda aquisição de linguagem é guiada pela faculdade de aquisição de linguagem inata" ${ }^{12}$ (VANPATTEN; WILLIAMS, 2015, p. 26).

[b] Hipótese do insumo "Input": na Teoria do Modelo Monitor, "o insumo compreensível é a única causa verdadeira de aquisição de segunda língua" (BROWN, 2007, p. 295). O insumo compreensível é aquele que deve ir um pouco além da sua atual competência, em termos de complexidade sintática. Este insumo é representado pela fórmula $i+1$. Segundo VanPatten e Williams (2015, p. 26), não há uma clareza sobre o que significa o 1 , tampouco o $i$; entretanto, "suas definições precisas não são importantes, desde que esses níveis de insumo nunca sejam isolados do insumo geral recebido" ${ }^{\prime 3}$. Porém, como observa Brown (2007), o insumo não pode estar além da capacidade de entendimento do aprendiz (i+2; i+3...), nem aquém de seu estágio atual de forma que não possa ser desafiado $(i+0)$.

[c] Hipótese do Filtro Afetivo: Krashen afirma que a melhor aquisição ocorre em ambientes onde a ansiedade é baixa e a defensividade ausente, ou seja, em contextos onde o "filtro afetivo" é baixo. VanPatten e Williams (2015, p. 27) ainda acrescentam que "aprendizes que estão confortáveis e têm uma atitude positiva em relação ao aprendizado de idiomas têm seus filtros baixos, permitindo acesso irrestrito a informações compreensíveis" ${ }^{14}$. Já em ambiente estressante, como aquele em que os aprendizes são forçados a produzir antes de se sentirem preparados, eleva-se o filtro afetivo, bloqueando o processamento de entrada de insumo.

Assim, como constatado anteriormente, a Teoria do Modelo Monitor, apesar da vagueza das definições de seus conceitos e da impossibilidade de verificação empírica, ainda encontra espaço relevante e se constitui em objeto de pesquisa na área da

\footnotetext{
${ }^{12}$ No original: these regularities occur because all language acquisition is guided by the innate language acquisition faculty.

${ }^{13}$ No original: their precise definitions are unimportant since these levels of input are never isolated from the general input.

${ }^{14}$ No original: learners who are comfortable and have a positive attitude toward language learning have their filters set low, allowing unfettered access to comprehensible input.

Revista Moara, n. 54, ago-dez 2019 ISSN: 0104-0944

Recebido em 07/10/2019

Avaliado em 18/11/2019
} 
Aquisição de Segunda Língua. Contudo, tem sido alvo de críticas consideráveis ao longo dos anos, por não poder afirmar com precisão se o conhecimento foi adquirido ou aprendido de fato. Até mesmo a Hipótese do Filtro Afetivo é criticada, por não apresentar uma teoria precisa e a identificação quando o filtro afetivo é alto ou baixo. ${ }^{15}$

A seguir, apresentamos o modelo da aculturação, de Schumann.

\section{O Modelo da Aculturação}

Como dito anteriormente, nossa concepção de língua é a de uso, e acreditamos que o Modelo de Aculturação de Schumann (1986), para a época atual, deve ser visto sob uma perspectiva mais ampla, não limitada somente a uma integração social e psicológica do aprendiz com o grupo da língua-alvo, uma vez que a própria internacionalização do processo de aprendizagem de línguas já é uma realidade e faz parte do cotidiano de aprendizes que se envolvem social e afetivamente com a língua estudada.

Para Schumann (1986), além de o Modelo de Aculturação estar intrinsecamente relacionado a uma integração sociopsicológica do aprendiz com o grupo da língua-alvo, o autor também parte da premissa de que é possível adquirir uma língua de forma natural e sem instrução formal, isto é, estando integrado e em permanente contato com falantes nativos à medida em que quanto maior for o grau de aculturação em que o indivíduo se encontra, maior será essa aquisição.

Quanto ao "sem instrução formal", em contextos educacionais brasileiros, onde as condições existentes são desafiadoras para o ensino de línguas estrangeiras, em escolas públicas, como carga horária reduzida (uma ou duas aulas semanais de 50 minutos) e um grande número de alunos por turma (média de 40 alunos por turma), consideramos a instrução formal importante, pois este tipo de instrução pode facilitar a o contato e a familiarização com o conteúdo, fazendo com que os aprendizes sejam instruídos e familiarizados com a língua.

Por outro lado, embora a instrução formal seja relevante, é inegável que uma boa parte dos aprendizes têm, atualmente, a possibilidade de se engajar em níveis diferentes

\footnotetext{
${ }^{15}$ Para leituras mais aprofundadas sobre as críticas, sugerimos a leitura Brown (2007), a partir da página 296; VanPatten e Williams (2015), a partir da página 31; Paiva (2014), a partir da página 34; e o artigo de Bezerra (2003), a partir da página 36.

Revista Moara, n. 54, ago-dez 2019 ISSN: 0104-0944

Recebido em 07/10/2019

Avaliado em 18/11/2019
} 
de aculturação por meio da tecnologia, por exemplo, usufruindo da oportunidade de se integrarem social e afetivamente com grupos (nativos ou não) de falantes da línguaalvo. Logo, o conceito de aculturação, hoje, reveste-se de uma roupagem atualizada, não mais limitada ao locus onde essa língua é falada, e sim, é resultante, principalmente, de fatores emocionais e sociais para com a língua escolhida.

Schumann (1978) apresenta uma série de fatores que influenciam a aquisição, e que são identificados em nove grupos: social, afetivo, personalidade, cognitivo, biológico, aptidão, pessoal, instrucional e insumo linguístico. Todavia, para a pesquisa realizada neste artigo, detivemo-nos apenas nas variáveis social e afetiva como potencializadoras da ASL em sala de aula.

Larsen-Freeman e Long (1991, p. 252-253) listam os seguintes fatores sociais analisados por Schumann:

a) Dominância social ou Padrões de dominação: este fator está relacionado à resistência (ou falta dela) que aprendizes de uma segunda língua têm em relação a culturas ou políticas dominantes. Ou seja, é quando um grupo cultural ou politicamente dominante oferece resistência em aprender a língua do grupo dominado, o mesmo acontecendo na situação inversa;

b) Estratégias de integração: este fator se refere às estratégias de aproximação e abertura com o grupo falante da segunda língua, envolvendo assimilação, preservação e adaptação. A assimilação acontece em decorrência da maximização do contato com o grupo, assimilando valores e estilo de vida do outro. A preservação é uma forma de resistência à cultura do outro, ou seja, preservam-se seus próprios valores e estilo de vida, estabelecendo, com isso, uma distância social com o grupo da língua-alvo. A adaptação é quando se se adapta ao grupo da línguaalvo, porém, mantendo seus próprios valores e estilo de vida;

c) Fechamento: é o fator que envolve o distanciamento da cultura dos falantes da segunda língua em relação ao aprendiz, fazendo-o manter contato apenas com elementos relacionados a sua própria cultura e grupos sociais de origem, reduzindo assim as oportunidades de aquisição, ou seja, quanto maior for o fechamento, menor é a possibilidade de se envolver socialmente e adquirir a língua e, quanto menor for o fechamento, maior será a aquisição da língua-alvo; 
d) Coesão e tamanho: de forma semelhante com o que ocorre no Fechamento, isto é, quanto maior o fechamento, menor será a possibilidade de se envolver socialmente com o grupo da língua-alvo, Schumann (1978) reitera que grupos grandes e coesos, que não falam a língua-alvo, acabam interferindo negativamente na aquisição, uma vez que se distanciam dessa língua por preferirem interagir mais na sua própria língua materna;

e) Congruência cultural ou Similaridade: este fator ressalta a empatia ou similaridade entre a cultura de origem e a cultura dos falantes da segunda língua;

f) Atitude: este fator diz respeito a quanto maior for a atitude positiva em relação à língua estudada, maior será a probabilidade de ASL;

g) Tempo de residência pretendido: está relacionado com a duração da estada de um indivíduo no ambiente da língua alvo. Quanto maior for o tempo dispendido nesse círculo, maior a probabilidade de aprender essa segunda língua e desenvolver contatos também com outros grupos.

Como dito anteriormente, em decorrência da própria era globalizada em que vivemos, as barreiras físicas e espaciais não mais são obstáculos para que o aprendiz se envolva afetiva, social e psicologicamente com uma segunda língua, principalmente, por causa dos recursos tecnológicos utilizados para esse fim. Acreditamos que todo aquele que se predispõe, mesmo à distância, ao estudo de uma língua-alvo, muito pode adquiri-la. Dessa forma, de acordo com os novos tempos, presumimos que os princípios dos fatores sociais elencados por Schumann podem potencializar e contribuir para o desenvolvimento da aquisição da língua estudada.

A seguir, apresentamos as variáveis afetivas apresentadas por Schumann. Essas variáveis são:

a) Choque linguístico: segundo Schumann, este fator é mais comum em adultos e está relacionado ao medo destes de errarem e de não conseguirem usar as palavras adequadamente, reduzindo, portanto, a oportunidade de desenvolverem a aquisição;

b) Choque cultural: para o autor, choque cultural é "a ansiedade resultante da desorientação encontrada ao se entrar em uma nova cultura" (SCHUMANN, 1978, p. 32). Como esse fator está relacionado à ansiedade, o aprendiz se depara com um 
alto nível de stress, o que redunda, consequentemente, interferência negativa na aquisição;

c) Motivação: esse fator se relaciona ao desejo de se tornar membro de outro grupo etnolinguístico, ou ter reconhecimento social e ou econômico por meio do conhecimento da segunda língua;

d) Permeabilidade do ego: pode ser entendida como a percepção que se tem dos limites da língua que, segundo Schumann, é muito mais comum na fase adulta. Este fator trata do quanto se está disposto a adquirir a língua-alvo. Ou seja, se o aprendiz não superar o choque cultural e o estranhamento com a nova língua, não tendo suficiente motivação e permeabilidade, não será possível adquirir a segunda língua completamente.

Logo, quando se trata de variáveis social e afetiva, presumimos que elas são fatores que muito podem contribuir para a aquisição de uma língua estrangeira, mesmo sabendo que nem todas essas variáveis se adaptam ao contexto educacional brasileiro, uma vez que nossos alunos não estão, nem nós, como professores de língua estrangeira, imersos e expostos cotidianamente à língua-alvo.

Cientes da condição de não estarmos expostos de maneira recorrente à línguaalvo, elencamos, segundo nossa compreensão, os fatores que mais se aproximam de nossa realidade, tais como as Estratégias de integração, Congruência cultural e Atitude, como variáveis sociais, por haver semelhança entre elas, pois acreditamos que quanto maior forem as estratégias de aproximação, abertura, identificação cultural e atitude positiva com o grupo falante da segunda língua, maior será a aquisição.

Já em relação às variáveis afetivas, consideramos relevante desenvolver em sala de aula a Permeabilidade do ego, pois trata da disposição para adquirir a língua-alvo, juntamente com a Motivação, sem a qual a aquisição de uma língua tornar-se-ia mais difícil. Dessa forma, levando em conta essas variáveis, presumimos que é possível criar ambientes propícios e motivacionais para que se aprenda a língua estudada e que pode até mesmo ser mediada por recursos tecnológicos.

Quando não há recursos tecnológicos na escola, acreditamos que a parceria pedagógica de professores e da instituição escolar é imprescindível como reação ao conformismo a toda e qualquer situação adversa que atravanque o ensino, e isso pode ser feito, por exemplo, lançando mão de recursos manuais, tais como a utilização de 
livros didáticos, de cartazes, de utensílios e objetos com o propósito de ensinar a línguaalvo, tendo sempre em mente que "precisamos ser sensíveis às normas culturais [e acrescentaríamos sensíveis à propria realidade local], à disposição do aluno de falar em aula e à pontos entre a extroversão extrema e a introversão que podem variar de aluno para aluno" (BROWN, 2007, p. 168). ${ }^{16}$

Diante dos fatos, considerar as variáveis social e afetiva pode ser uma estratégia para adquirir uma segunda língua, porquanto é uma oportunidade de desenvolver a língua estudada aguçando no aprendiz o senso crítico, a percepção de como usar a língua (levando em consideração tanto o contexto quanto a situação) e também a oportunidade de aproximar os aprendizes ao universo da língua-alvo, fazendo com que essa língua passe a fazer parte do cotidiano do aprendiz e, permitindo, sempre que possível, que eles tenham um filtro afetivo baixo, para que a aquisição seja, de fato, alcançada.

\section{Conclusão}

Desenvolver as variáveis social e afetiva contribui para a aquisição de uma segunda língua, porquanto quanto maior for a afetividade e identificação com a língua estudada, maior será a probabilidade de essa língua ser adquirida. Em relação à variável afetiva, concordamos com Brown (2007, p. 152) quando menciona que o domínio afetivo é difícil de se descrever cientificamente, uma vez que "um grande número de variáveis está implícito na consideração do lado emocional do comportamento humano no processo de aprendizado de uma segunda língua"17. Porém, descartar esse domínio não seria razoável, pois o processo de aquisição parece alavancar quando se valoriza e se responde positivamente à essa língua. ${ }^{18}$

Quanto à variável social, é importante destacar que nenhuma sociedade existe sem cultura. De acordo com Brown (2007, p. 189), "a cultura estabelece para cada

\footnotetext{
${ }^{16}$ No original: We need to be sensitive to cultural norms, to a student's willingness to speak out in class, and to optimal points between extreme extroversion that may vary from student to student.

${ }^{17}$ No original: a large number of variables are implied in considering the emotional side of human behavior in the second language learning process.

${ }^{18}$ Para maiores informações sobre outros fatores afetivos (autoestima, inibição, ansiedade, empatia, extroversão, introversão, motivação) na aquisição de segunda língua, sugerimos ler o capítulo 6 de Brown (2007), a partir da página 152.
} 
pessoa um contexto de comportamento cognitivo e afetivo, um modelo para a existência pessoal e social" ${ }^{\prime 19}$. No caso da aquisição de segunda língua, é relevante enfatizar que a cultura do outro, ou seja, a língua-alvo do outro, não precisa nem deve se sobrepor à cultura de quem a estuda. Pelo contrário, cada uma delas apresenta suas próprias características, peculiaridades e identidade, como reiteramos enfaticamente no texto, corroborando, portanto, o pensamento de Paiva (2014, p. 52) quando diz que "a adoção de estilos e valores não é condição necessária para uma aquisição bem-sucedida, mas sim o contato social e o psicológico com o grupo da língua-alvo".

Assim, muito embora o Modelo de Aculturação não explique a aquisição em contextos onde a língua-alvo não é falada, seus princípios são relevantes e atuais, pois seu foco leva em conta questões relacionadas à integração social e psicológica do aprendiz com o grupo dessa língua-alvo. Olhar para esse modelo e trazê-lo para o ensino e aprendizagem de línguas, pode contribuir para a aquisição, sem deixar de considerar a vasta complexidade do processo de adquirir uma segunda língua, questão essa que não pode ser atribuída apenas ao Modelo de Aculturação.

Quanto às controvérsias e inúmeras tentativas teóricas para explicar o processo de ASL, acreditamos que as teorias apresentadas neste artigo podem trazer luzes e ampliar o entendimento acerca de como se dá a aquisição de qualquer língua humana, e sua complexidade pode acontecer em circunstâncias e ambientes variados, que vão desde uma imersão em loco em países que falam a língua-alvo, até mesmo a aquisição decorrente da aprendizagem da língua em países que não compartilham de uma raiz linguística da língua estudada.

Mesmo não sendo unanimidade e encontrando resistência entre os pesquisadores de ASL por se deter na descrição do que é diretamente observável e na apresentação de um modelo de língua, acreditamos que a teoria behaviorista influenciou e continua influenciando o ensino de línguas, pois até mesmo o conceito de língua, como um conjunto de estruturas básicas, ainda prevalece em muitos materiais didáticos.

Por fim, a influência da Teoria do Modelo Monitor ainda repercute por tentar relacionar e explicar uma variedade de fenômenos no aprendizado de idiomas e que muito tem contribuído para se entender as pesquisas sobre a ASL, permitindo-nos reflexionar acerca de algumas hipóteses interligadas amplamente divulgadas no ensino

\footnotetext{
${ }^{19}$ No original: culture establishes for each person a context of cognitive and affective behavior, a template for personal and social existence.

Revista Moara, n. 54, ago-dez 2019 ISSN: 0104-0944

Recebido em 07/10/2019

Avaliado em 18/11/2019
} 
de línguas, tais como a Hipótese da aquisição-aprendizagem, a Hipótese do monitor, a Hipótese do Input e a Hipótese do Filtro Afetivo.

Assim, acreditamos que cada teoria apresentada e discutida aqui coopera para o entendimento de como acontece o processo de ASL, funcionando, portanto, como coadjuvantes e não como antagonistas, não apresentando, também, uma resposta definitiva, entretanto, lançando raios de luzes que têm iluminado a compreensão de como se adquire uma língua.

\section{REFERÊNCIAS}

BEZERRA, I. C. R. M. Aquisição de segunda língua de uma perspectiva linguística a uma perspectiva social. SOLETRAS, Ano III, nº 05 e 06. São Gonçalo: UERJ, p. 31-52, 2003.

BROWN, H. D. Principles of language learning and teaching. 5th ed., New York: Pearson Education. 2007.

COHEN, D. J. B. Watson: The founder of behaviorism. London: Routledge \& Kegan Paul. 1979.

CONSOLO, D. A.; SILVA, V. L. T. Desenvolvimento da Proficiência Oral em Inglês de alunos universitários: análise de tarefas e da qualidade das interações verbais. In:

SILVA, K. A. da. et al. (Orgs.) A Formação de Professores de Línguas: novos olhares. v. 1, Campinas, SP: Pontes Editores, 2011, p. 127-146.

COOK, V. Linguistics and Second Language Acquisition. Basingstoke: Macmillan, 1993.

CORREA, L. M. S. Aquisição da linguagem: uma retrospectiva dos últimos trinta anos. D.E.L.T.A., Vol. 15, No Especial, p. 339-383, 1999.

DULAY, H.; BURT, M. Creative construction in second language learning and teaching. In: BURT, M.; DULAY, H. (Eds.) On TESOL'75: New directions in second language learning, teaching and bilingual education. Washington, DC: TESOL, 1975, p. 21-32.

ELLIS, R. The study of second language acquisition. Oxford: Oxford University Press, 2008. 
GASS, S. M.; SELINKER, L. Second language acquisition: An introductory course. Hillsdale, NJ, US: Lawrence Erlbaum Associates, Inc. 1994.

GASS, S. M.; SELINKER, L. Second language acquisition. An introductory course. 3rd ed. New York: Routledge, 2008.

KRASHEN, S. D. The Input Hypothesis: Issues and Implications. New York: Longman, 1985.

LANTOLF, J. P.; THORNE, S. L.; POEHNER, M. E. Sociocultural theory and second language development. In: VANPATTEN, B.; WILLIAMS, J. (Eds.) Theories in second language acquisition: an introduction. 2nd Edition. New York: Routledge. 2015, p. 207-226.

LARSEN-FREEMAN, D. A complexity approach to second language development/ acquisition. In: ATKINSON, D. (Ed.). Alternative Approaches to Second Language Acquisition. Abingdon: Routledge, 2011, p. 48-72.

LARSEN-FREEMAN, D.; CAMERON, L. Complex systems and Applied Linguistics. Oxford: Oxford University Press, 2008.

LARSEN-FREEMAN, D.; LONG, M. An Introduction to Second Language Acquisition Research. London: Longman, 1991.

LITTLEWOOD, W. Foreign and Second Language Learning: Language Acquisition Research and its Implications for the Classroom. Cambridge: Cambridge University Press, 1984.

MCLAUGHLIN, B. Theories of Second Language Learning. London: Edward Arnold, 1987.

MOITA LOPES, L. P. Oficina de linguística aplicada. Campinas, SP: Mercado de Letras, 1996.

MARCONI, M. A.; LAKATOS, E. M. Fundamentos da Metodologia Científica. 5a edição. São Paulo: Editora Atlas, 2003.

ORTEGA, L. Understanding Second language acquisition. New York: Routledge. 2013. 
PAIVA, V. L. M. O. Como o sujeito vê a aquisição de segunda língua. In: CORTINA, A.; NASSER. S. M. G. C. (Orgs.) Sujeito e Linguagem. São Paulo: Cultura Acadêmica, 2009, s/p. Disponível em: http://www.veramenezes.com/sujeito.pdf. Acesso em: 01 Out. 2019.

PAIVA, V. L. M. O processamento metonímico/metafórico à luz da teoria do caos/complexidade. Revista Portuguesa de Humanidades-Estudos Linguísticos. Braga, v.15, n.1, p. 51-66, 2011.

PAIVA, V. L. M. O. Aquisição de segunda língua. São Paulo: Parábola Editorial, 2014.

PRODANOV, C. C.; FREITAS, E. C. de. Metodologia do trabalho científico: Métodos e Técnicas da Pesquisa e do Trabalho Acadêmico. Novo Hamburgo/RS: Universidade FEEVALE, 2013.

QUEVEDO-CAMARGO, G. Breve história da evolução do construto proficiência em línguas. Em Aberto, Brasília, v. 32, n. 104, p. 27-44, jan./abr. 2019

SCARAMUCCI, M. V. R. Proficiência em LE: considerações terminológicas e conceituais. Trabalhos em Linguística Aplicada, Campinas, n. 36, p. 11-22, jul./ dez. 2000 .

SCHUMANN, J. H. Research on the acculturation model for second language acquisition. Journal of Multilingual and Multicultural Development, 7(5), 379-392, 1986.

SCHUMANN, J. H. The Acculturation Model for Second-Language Acquisition. ln: GINGRAS, R. C. (Org.) Second-Language Acquisition \& Foreign Language Teaching. Washington: Center for Applied Linguistics, 1978, p. 27-50.

SKINNER, B. F. Verbal Behavior. Cambridge: Prentice Hall, 1992.

STRAPASSON, B. A. A caracterização de John B. Watson como behaviorista metodológico na literatura brasileira: possíveis fontes de controle. Estudos de Psicologia, 17(1), p. 83-90, 2012.

VANPATTEN, B.; WILLIAMS, J. (Eds.) Theories in second language acquisition: an introduction. 2nd Edition. New York: Routledge. 2015. 